\title{
CARACTERÍSTICAS DAS RELAÇÕES DE AJUDA NA AMAZÔNIA BRASILEIRA: APONTAMENTOS A PARTIR DO ESTUDO DOS HABITANTES DA BACIA DO RIO TEJO, ACRE*
}

Roberto Sanches Rezende

\section{Introdução}

O objetivo deste artigo é examinar as relações chamadas de "ajuda" entre habitantes da bacia do rio Tejo, Acre. Baseado em etnografia, o texto introduz as diferentes classificações locais para as relações de troca e as características distintivas da ajuda, em especial seu papel na construção de laços sociais e aproximação entre pessoas. Em seguida, sugere-se que as relações de ajuda entre comunidades amazônicas não devem ser compreendidas apenas a partir dos aspectos materiais da troca, e que são relações que constroem e se fundamentam em relações de consideração entre as pessoas. Argumenta-se também que esse conjunto de relações não configura um sistema de trocas voltado para o interior da comunidade ou igualitário do ponto de vista material, mas sim em uma economia política própria que extrapola o nível comunitário e influencia historicamente as relações com agentes externos, de mercado e de Estado.

Na literatura antropológica sobre comunidades amazônicas, o tema da ajuda é recorrente e está registrado em diversas etnografias sobre a região. No geral, a ajuda se apresenta como uma relação de troca que permite o desempenho das atividades econômicas das casas de ribeirinhos, caboclos, seringueiros, castanheiros e outros povos e comunidades amazônicas. Entre uma variedade desses grupos, a ajuda é, por exemplo, a forma mais comum de encontrar trabalho extra nos momentos de pico de esforço em construções e roçados.

Um relato pioneiro sobre relações de ajuda aparece na etnografia de Charles Wagley. Publicado originalmente em 1953, o trabalho já descrevia as principais características dessas relações tão comuns na 
Amazônia contemporânea. Wagley nos apresentou unidades domésticas compostas por esposas e filhos que ajudavam (help, no original) seus maridos e pais nos roçados. Apontou que relações de ajuda estavam relacionadas ao apoio entre pessoas próximas, principalmente em momentos de dificuldade, descrevendo que determinadas relações de parentesco e aliança pressupunham outras de ajuda mútua. Também registrou que a possibilidade de ascensão social na pequena comunidade de Itá passava sempre pela ajuda de um padrinho influente (Wagley 1976:137).

No início da década de 1990, Deborah Lima-Ayres nos forneceu outro registro dessas relações. Em sua tese sobre caboclos amazônicos, ela interpretou as relações de ajuda na Amazônia como relações de reciprocidade, com ciclos que se iniciavam sempre com um pedido. Seguindo o clássico trabalho de Mauss sobre o dom, Lima-Ayres afirmou: "Uma pessoa só é convidada por alguém que está querendo retribuir [reciprocate], por isso o pedido de ajuda é o equivalente a uma dádiva inicial" (Lima-Ayres 1992:138). A autora também contribuiu para uma melhor compreensão das relações de ajuda ao correlacioná-las ao parentesco e a um padrão de ocupação do território, atentando para o papel que a ajuda tinha na escolha da morada e na conformação territorial em comunidades amazônicas: "Residir próximo a parentes dá mais segurança de que a troca [entre vizinhos] ocorrerá do que quando os vizinhos não são aparentados" (:138).

Alguns anos depois, Mark Harris publicou um novo trabalho em que relações de ajuda na Amazônia eram citadas. Suas proposições sobre a ajuda foram além das de Lima-Ayres, sugerindo que ela era um elemento-chave para compreender as relações de cooperação no interior de grupos de casas ligadas por parentesco. Harris afirmou que o princípio de ajuda "significava cooperação e harmonia entre pessoas que estão dividindo suas vidas cotidianas" (Harris 2000:86), estabelecendo diferenciações entre as trocas no interior e no exterior das comunidades: “Entre parentes, 'trabalho' é conceitualizado como ajuda, enquanto entre estranhos e não parentes ele é avaliado em termos de produtos e seus valores" (:86). Nesta perspectiva, a ajuda teria características de uma troca desinteressada, fundamentada em mutualidade, e na qual o cálculo de que quem dá ou faz o quê não tem vez. Ela também seria limitada a um espaço social ocupado apenas por parentes, e oposta às relações fora desses limites, por sua vez marcadas por cálculos objetivos. De um lado, têm-se as relações entre as pessoas e, do outro, os valores das coisas. Assim, a ajuda, para além de uma relação de reciprocidade, seria uma chave analítica para encontrar limites entre formas de relação e entre grupos sociais. 
Mais recentemente, outros trabalhos sobre povos e comunidades amazônicas passaram, de uma maneira ou de outra, pelo tema da ajuda, recuperando os aspectos centrais apontados pelos trabalhos anteriores. Therezinha Fraxe resgatou sua correlação com o parentesco e com a possibilidade de mobilizar trabalhadores extras, afirmando que as "famílias ribeirinhas [da comunidade São Francisco, em Carreiro da Várzea (AM)] estabelecem, geralmente, as práticas de ajuda mútua do tipo parceria ou mutirão, caso se trate de grupos aparentados (família extensa)" (Fraxe 2004:122). Elane Silva, estudando um contexto de forte influência da Igreja Católica na comunidade de Taruaru em Tabatinga (AM), retomou as características agregadoras da relação, sustentando que a "ajuda mútua funciona como o delimitador do espaço social" e que funciona na "objetivação do sentimento de comunidade", ocorrendo de forma espontânea e colaborativa (Silva 2007:47, 139).

Já Juliana Machado, em tese sobre as relações entre plantas e pessoas na ilha Caviana (PA), seguiu o espírito das afirmações de Deborah Lima-Ayres, apontando que as relações de ajuda, manifestadas na formação de grupos de trabalho entre parentes, amigos e vizinhos, seriam uma forma de reciprocidade importante, assumindo características de uma reciprocidade generalizada, na qual "todos os envolvidos esperam ser ajudados quando precisarem" (Machado 2012:141). Outro trabalho, sobre papéis de gênero e redes de relações de casais do rio Araraiana, município de Ponta de Pedras (PA), sugeriu que as relações de ajuda material entre vizinhos podem ser o resultado das condições econômicas de ribeirinhos amazônicos, tornando cada unidade doméstica dependente das demais para sua sobrevivência (Silva 2010:611).

Em resumo, dentre as principais características que esses trabalhos atribuíram às relações de ajuda estão seu papel fundamental no funcionamento das economias domésticas de povos e comunidades amazônicas, suas características de dádiva, sua imbricação com as relações de parentesco, e sua correlação com a ocupação do espaço e a delimitação de grupos de cooperação. Passo agora à análise do estudo de caso, de modo a agregar mais elementos ao debate sobre a caracterização dessas relações na Amazônia brasileira. Em especial sobre a correlação entre ajuda e a proximidade social de modo a demonstrar como determinadas relações criam a proximidade que faz a ajuda aparentar ser desinteressada e generalizada no âmbito das comunidades. 


\section{Relações de troca no Tejo}

No extremo oeste do estado do Acre, na bacia do rio Tejo, município de Marechal Thaumaturgo, habitam grupos de pequenos agricultores, descendentes de migrantes nordestinos e indígenas que foram incorporados aos seringais que funcionaram entre os finais dos séculos XIX e XX na região. Esses antigos seringueiros vivem atualmente na Reserva Extrativista do Alto Juruá, ${ }^{1}$ e estão organizados espacialmente em unidades territoriais chamadas de comunidades, formadas, em média, por 18 casas. ${ }^{2}$ Por sua vez, essas comunidades são divididas em grupos de casas, constituídos por casas que cooperam em atividades econômicas e políticas e que se organizam em torno de uma liderança comum.

Embora a organização territorial em comunidades tenha sido uma introdução recente, influenciada pela chegada de serviços básicos de cidadania e pela mudança nas atividades produtivas na região, ${ }^{3}$ a organização das atividades econômicas e políticas através de grupos de casas em cooperação é mais antiga. A primeira descrição desses grupos de casas que cooperam foi fornecida no início da década de 1990 por Mauro Almeida, que os chamou de casas-ampliadas e os descreveu como "um conjunto de casas próximas ligadas entre si" e que "podiam agir como uma unidade de consumo ou de cooperação técnica, bem como figurarem como uma unidade 'moral' sob a liderança de uma casa mais velha" (Almeida 1992:179). Almeida mostrou que a composição dos grupos de casas apresentava um padrão de parentesco próximo entre os chefes de cada casa, sendo formados por casas de irmãos, pais, filhos, maridos de filhas e irmãs (:334).

Entre 2013 e 2014, realizei pesquisa de campo em um desses grupos de casas da bacia do rio Tejo, com interesse em observar as relações de cooperação estabelecidas entre as casas durante um ciclo agrícola, momento de pico na demanda de trabalho ao longo do ano. ${ }^{4} \mathrm{O}$ grupo de casas estudado estava organizado em torno da casa de seu Iraçu Nogueira, a quem todas as demais casas estavam ligadas por parentesco, sendo chefiadas por seus filhos Hilarino, José, Francisco e Vivaldo, e por seu genro Adonis. Além desses filhos próximos, Iraçu tinha nas redondezas mais duas filhas casadas com Juarez e Jonas, dois irmãos que compunham um grupo de casas vizinho, orientado pela figura de seu Osvaldo, pai deles.

Cada uma das casas que compunha o grupo orientado pela figura de Iraçu era responsável pela execução de seus roçados, tendo que mobilizar trabalhadores para cada fase do plantio. Ao fim, cada casa também ficaria com os produtos de seus roçados, tendo autonomia para consumo e comercialização. Durante o ciclo agrícola iniciado em julho de 2013 e terminado 
em fevereiro de 2014, as casas do grupo se engajaram em diversas trocas para obter trabalhadores necessários às fases de broca, queima, coivara e plantio das áreas dos roçados. ${ }^{5}$

A maior parte do trabalho empregado nas atividades agrícolas do grupo de casas era proveniente do interior do próprio grupo. Dos 152 dias de trabalho necessários à abertura e ao plantio dos roçados, 120,5 dias vieram da própria casa dona do roçado ou de casas vizinhas do mesmo grupo, o que representava quase $80 \%$ do trabalho total empregado. Desses 120,5 dias de trabalho, 98 foram das próprias unidades domésticas donas dos roçados (era o trabalho do chefe da casa, de sua esposa, filhas e filhos), enquanto os outros 22,5 dias foram provenientes de outras casas do grupo. O restante do trabalho empregado nos roçados veio de fora do grupo de casas. Uma parte pequena dele, dos genros de Iraçu, Jonas e Juarez, que forneceram 7 dias de trabalho. Outra parte, 24,5 dias de trabalho, foi proveniente de pessoas de outras comunidades.

As relações de troca que permitiram às unidades domésticas trazerem trabalhadores adicionais a seus roçados, do interior do próprio grupo ou mais distantes, eram classificadas pelas pessoas de diferentes maneiras. Havia trocas de dias, empeleitas, diárias, ajudas e mutirões. As diferenças entre as trocas do tipo empeleita, diária, e troca de dias residiam nos acordos pelo pagamento do trabalho inicialmente fornecido. A empeleita era um acordo de preço fixo por serviço determinado (como a derrubada completa de um roçado). A diária era um acordo de pagamento estipulado por uma quantia fixa de dinheiro (ou produto) por unidades de tempo (um dia ou meio dia), multiplicada pelo tempo despendido para a realização do serviço (se um trabalhador levasse dois dias para fazer um serviço com diária estipulada em $\mathrm{R} \$ 30$, receberia $\mathrm{R} \$ 60$, por exemplo). Já a troca de dia era uma forma de troca de trabalho na qual uma casa fornecia trabalho a outra casa e depois recebia como retribuição trabalho equivalente, calculado em porções de tempo (dia, ou meio dia), de acordo com a idade e o sexo dos trabalhadores (homens, mulheres e crianças). ${ }^{6}$ Já o termo mutirão, ou adjunto, era utilizado apenas em atividades coletivas de trabalho relacionadas à construção ou à manutenção de algo de uso coletivo do grupo de casas. Mutirões eram feitos para limpar caminhos, dar manutenção à casa de farinha ou ao campo de gado, todas estas áreas de uso coletivo.

Analisando as trocas em termos materiais, a empeleita e a diária eram formas que uma casa tinha de obter trabalhadores adicionais utilizando a transferência de dinheiro ou outros objetos trocados por trabalho; a troca de dia era uma maneira de conseguir mais trabalho sem precisar transferir bens; e o mutirão era uma forma de manutenção de meios de produção adminis- 
trados pelo grupo de casas que mobilizava trabalho sem precisar transferir bens, mas na qual cada casa fornecia trabalho ao grupo (outra possibilidade interpretativa é que cada casa fornecia uma fração de seu trabalho a todas as outras, ao mesmo tempo em que recebia o equivalente de cada uma). Nas relações classificadas como ajuda não havia, no entanto, características materiais peculiares. Eram chamadas ajuda várias formas de troca, sendo impossível definir essa relação em termos de circulação de bens e trabalho. As pessoas utilizavam o termo para se referirem a trocas que podiam ser classificadas como trocas de dias, pagamentos de diárias ou empeleitas. No geral, em situações de troca, as pessoas diziam que determinado sujeito vinha ajudar no roçado e, apenas quando perguntadas sobre o acordo para pagamento da ajuda, falavam em trocas de dias, diárias ou empeleitas. Dessa forma, o uso do termo ajuda era capaz de abarcar todos os demais tipos de troca, apontando para uma relação que extrapolava os aspectos materiais.

\section{Características da ajuda}

Uma hipótese inicialmente utilizada para compreender as relações de ajuda é a de que elas eram relações de dádiva, no sentido clássico atribuído por Marcel Mauss (2003). Ao longo do ciclo agrícola, por exemplo, as casas que iniciavam seus roçados antes que as demais requisitavam às outras casas trabalhadores adicionais. Depois, retribuíam o trabalho prestado fornecendo trabalhadores aos roçados daquelas com quem estavam endividadas.

Numa relação básica de ajuda, há sempre aquele que precisa e aquele que pode fornecer o que o outro precisa. Estas duas situações são expressas pelos habitantes do Tejo através dos termos precisão e condição, respectivamente. Aquele que tem precisão pedirá algo (ou deixará implícito em suas ações e falas que precisa de algo) àquele que tem condição. Este, idealmente, deve fornecer o que for pedido, deixando o que recebe endividado para com ele. No futuro, o que recebe deve retribuir quando encontrar o que deu em uma condição de precisão. Outra característica básica desse sistema de reciprocidade é que as pessoas e as casas que entram em uma relação de ajuda estão sempre em posições distintas no momento da troca, mesmo que essas posições se invertam no futuro. Há constantemente aquele que precisa e aquele que tem condição de fornecer o que o outro precisa.

Esse sistema básico de reciprocidade começa a se complexificar quando se coloca em questão a escassez de bens e de trabalhadores que cada casa consegue mobilizar. Quando uma casa requisita trabalhadores adicionais para seu roçado, por exemplo, ela sabe que terá que retribuir no futuro. Cabe 
ao chefe de cada casa planejar a distribuição do tempo de seus trabalhadores ao longo do ciclo agrícola, requisitando trabalhadores adicionais para seus roçados, mas também evitando se endividar demasiadamente, de modo que consiga retribuir no futuro as ajudas prestadas a ele. Assim, a gestão dos trabalhadores da casa deve levar em consideração sua capacidade de pagar o endividamento de dias de trabalho no futuro ao mesmo tempo em que deve prestar atenção à capacidade das outras casas de fornecerem trabalho quando requisitado, sem que inviabilize a existência das casas individuais ou a harmonia do grupo de casas. Uma das características da ajuda, portanto, é que ela não pode ser fornecida de maneira ilimitada, sendo diretamente influenciada pelas condições materiais, em bens e trabalhadores, de cada casa. Nenhuma casa tem condição de ajudar indiscriminadamente.

Esse cálculo da necessidade de trabalho das casas individuais em face das demais pode ser exemplificado com o planejamento do plantio e da colheita do arroz do grupo de Iraçu. Na época do plantio, Hilarino conversou com seu pai sobre a ordem dos plantios de cada casa, para que eles fossem "espaçados" no tempo e não resultassem em coincidência na maturação e apanha, quando cada casa necessitaria de trabalho das demais. Essa preocupação com o gerenciamento coletivo dos roçados das casas próximas tinha como pressuposto que, no momento em que cada uma delas precisasse de trabalho extra para a colheita, as demais teriam condição de fornecê-lo.

Quando uma pessoa ou casa não podia fornecer a ajuda pedida por outrem, a formalidade requisitava um pedido de desculpas. No geral, um sujeito dizia ao outro que entendia a situação ou precisão dele, mas que não poderia ajudá-lo porque não tinha o que dele era pedido, ou não tinha condição naquele momento por estar comprometido com atividades de sua casa ou de auxílio já prometido a uma pessoa. Ao se negar o pedido de ajuda, havia o risco de o ato ser entendido como uma desconsideração à precisão de quem estava solicitando ajuda, um tipo de menosprezo ao outro. Ao justificar esta incapacidade por já ter comprometido seus trabalhadores ou seus bens em outra atividade, aquele que negava tentava mostrar para o que pedira que a sua própria casa tinha precisão daqueles bens e trabalhadores naquele momento e que a negativa da ajuda não estava fundamentada em atritos ou animosidades entre eles.

A negativa injustificada a uma ajuda pedida poderia gerar um sentimento de desconsideração e consequente afastamento social. Neste ponto se revela mais um aspecto fundamental das relações de ajuda: que elas também participam da construção e da atualização de relações de consideração entre pessoas. Consideração é um termo local utilizado para se referir a relações entre pessoas que se gostam, que têm apreço uma pela outra, e que por isso 
se tornam parceiros frequentes de trocas. Considerar alguém envolve não apenas o sentimento de sentir-se bem na presença do outro, mas também pensar e estar atento ao que o outro necessita. Considerar significa levar em consideração a necessidade do outro, demonstrar preocupação e dar apoio. Seu uso na bacia do rio Tejo se assemelha ao uso do termo tal como descrito por João de Pina-Cabral e Vanda Silva em seus estudos no sul da Bahia: há um "elemento de crédito na consideração que significa que aqueles para quem eu tenho consideração esperam que eu lhes dê algo antes de dar aos outros para com quem se considera que eu tenha menos consideração" (Pina-Cabral \& Silva 2013:25). Assim, ao decidirem como mobilizar seus trabalhadores e a quem pedir ajuda, as casas da bacia do rio Tejo também estão decidindo com quem aproximam relações e por quem demonstram apreço. A ajuda não se limita aos aspectos materiais da troca, assumindo características geradoras e mantenedoras de relações sociais.

\section{Troca e proximidade}

Voltemos aos exemplos etnográficos para tratar da correlação entre a ajuda e a proximidade social na bacia do rio Tejo. Começo com um breve relato das trocas realizadas pela casa de Hilarino, um dos filhos de seu Iraçu, ao longo do ciclo agrícola de 2013-2014 para a produção de arroz, seu produto principal voltado à comercialização naquele ano.

Em 2013, os trabalhos de Hilarino com arroz começaram com o pedido de ajuda a seu pai para a realização da medição da área para a abertura do roçado em uma região de mata bruta. Depois, Hilarino empeleitou a limpa da vegetação rasteira com um sobrinho (filho de uma irmã de sua esposa) que morava num afluente das cabeceiras do Tejo (comunidade Dos Índios, distante um dia de viagem), e a derrubada dos troncos das árvores com seu cunhado Juarez (da mesma comunidade de Hilarino, mas de um grupo de casas distinto). Botou fogo sozinho e encoivarou o roçado com a ajuda de sua esposa, Iza. Durante o plantio, recebeu ajuda de seu pai, seus irmãos e seu cunhado (todos parte do mesmo grupo de casas). Já perto do período de apanha, participou de um mutirão com essas mesmas pessoas para reconstruir o telhado da casa de farinha, onde o arroz seria torrado, e para limpar os caminhos dos roçados até lá. Durante a apanha, recebeu ajuda de várias pessoas: de sua casa veio sua filha mais velha; do grupo de casas vieram seus irmãos e um de seus cunhados com a esposa e o filho mais velho; de outras comunidades, vieram um sobrinho (da distante Dos Índios), três conhecidas da comunidade vizinha (Foz do Tejo), e um sobrinho 
de sua madrasta (que estava morando na sede do município, distante uma hora de canoa motorizada). Durante a torra do arroz, Hilarino ainda contou com a ajuda de um sobrinho.

No decorrer dessas atividades, a palavra "ajuda" foi utilizada de maneira genérica para explicar relações com pessoas de diferentes lugares e que se engajaram nas atividades agrícolas através de formas distintas de pagamento por seus trabalhos. Hilarino considerava ajuda todo o apoio que recebeu ao longo do ciclo agrícola, fosse ele proveniente da sua casa (esposa e filha), do grupo de casas do qual fazia parte (pai, irmãos, cunhado e sobrinho), da comunidade vizinha (Foz do Tejo), ou de comunidades distantes (Dos Índios e mesmo de pessoas morando na vila Thaumaturgo).

Embora os exemplos acima neguem a hipótese de que as relações de ajuda ocorrem apenas entre casas vizinhas e aparentadas ou no interior de uma determinada comunidade, a análise de como ocorreu a retribuição de Hilarino às ajudas prestadas não possibilita descartar completamente a correlação entre convívio próximo e determinadas práticas de troca. Para pessoas de outras comunidades, Hilarino retribuiu as ajudas que recebeu, na maior parte das vezes, com o pagamento em diárias, fosse em dinheiro ou em quilos de arroz (estipulados previamente em unidades diárias). Para pessoas do grupo de casas, as formas de pagamento pela ajuda foram variadas. Iraçu não cobrou nada por medir as áreas e nem por ajudar no plantio do arroz. Já os irmãos de Hilarino e seu cunhado Adonis realizaram o plantio como forma de retribuição a outras ajudas que Hilarino dera a eles anteriormente (troca de dias - por ter conhecimentos de mecânica, Hilarino costumava ajudar os demais com o conserto de todos os motores do grupo de casas, fossem eles de uso coletivo, como motores da peladeira de arroz, ou de moagem da casa de farinha, ou individual, como motores de popa para canoa. Hilarino também havia ajudado alguns deles em roçados e outras atividades).

Assim, as ajudas recebidas ao longo de todo o ciclo agrícola, advindas de casas próximas e distantes, foram retribuídas de maneiras distintas. Embora sempre classificadas como ajuda, essas relações guardam diferenças quando analisadas as formas de retribuição e a distância social dos sujeitos. Se classificarmos as retribuições das ajudas em ciclos curtos e longos de retribuição, será possível ver um padrão no comportamento de Hilarino. Para pessoas e casas mais distantes (fora do limite de seu grupo de casas), Hilarino retribuiu na maioria das vezes em um ciclo curto (com pagamento em dinheiro ou em produtos). Para as pessoas de seu grupo, ele retribuiu (ou recebeu retribuição) em ciclos longos (com trabalhos que seriam prestados no futuro, mas sem especificar as ocasiões). 
Quando olhamos para os dados das relações de troca de todas as casas do grupo de Iraçu no decorrer de um ciclo agrícola, a correlação entre proximidade social e o tipo de pagamento empregado nas relações de ajuda se confirma. Se classificarmos as trocas de todas as casas em "acerto prévio" (no qual o pagamento pela troca é negociado de antemão, na forma de diárias ou empeleita) ou "acerto futuro" (em que não se estipula um pagamento prévio), e de acordo com a proximidade entre as pessoas que trocam (se fazem parte do mesmo grupo de casas, da mesma comunidade ou se são de comunidades vizinhas e distantes), há uma correlação entre a distância social e o tipo de acerto pela retribuição das ajudas prestadas. No que se refere às trocas ocorridas entre as casas do grupo orientado em torno de Iraçu, apenas meio dia de atividades trocadas foi retribuído com dinheiro, enquanto os demais 22 dias de trabalho trocados não tiveram retribuições estipuladas de antemão. Nas trocas que as casas do grupo de Iraçu se envolveram com outras casas da comunidade, cinco dias de trabalho foram retribuídos com acerto prévio e outros dois com acerto futuro. Já quanto às trocas com casas de outras comunidades, apenas um dia de trabalho foi retribuído com acerto futuro e 23,5 dias o foram com acerto prévio, o que representa quase a inversão completa em relação às trocas entre as casas do grupo de casas.

Os dados apontam para a possibilidade de repensarmos a correlação entre a ajuda e o espaço no caso do Tejo da seguinte maneira: a principal marca distintiva das relações de troca no interior dos grupos de casas é o estabelecimento de trocas em ciclos mais longos de retribuição. Nestes, a consideração entre as pessoas exerce papel fundamental. Ela representa o alto grau de confiança entre parceiros de troca, fornecendo aos sujeitos a segurança de que os parceiros preferenciais de troca olhem pela necessidade um do outro no futuro, considerando a precisão e a condição de cada um no momento de decidir sobre suas próprias ações. Essa segurança, por sua vez, é um tipo de esperança criada a partir de relações anteriores de ajuda e que foram bem sucedidas, o que permite a uma pessoa prever com boa margem de acerto o comportamento de seu parceiro de troca no futuro.

Nesse contexto, minha sugestão é de que a formação de grupo de casas tem a ver com relações duradouras e consideradas boas entre as pessoas, que podem remontar a cadeias de ajuda que geram e mantêm a consideração e a confiança necessárias tanto na convivência próxima quanto nos ciclos longos de retribuição. Essas cadeias de ajuda podem resultar de vínculos prévios de parentesco, dados pela criação ${ }^{7}$ (que gera as relações de pai, mãe, irmãos, mãe e filhas), ou resultarem em parentesco (através de casamentos, apadrinhamentos e compadrios). Neste caso, ao invés de os grupos de cooperação delimitarem relações de ajuda, estamos tratando de um fenômeno inverso, 
no qual são as relações de ajuda que têm papel importante na delimitação de grupos de cooperação. Essa proposição condiz também com exemplos etnográficos da bacia do rio Tejo, nos quais pais, filhos e vizinhos se mudam de determinadas localidades após conflitos com pessoas próximas (Almeida 1992:177-183; Rezende 2016:51). A harmonia do grupo de casas resulta da consideração entre os sujeitos, que permite uma negociação constante entre necessidades e pontos de vista dos parceiros. Quando um dos parceiros se sente desconsiderado, o melhor a fazer é se retirar do grupo de casas e tentar construir relações em outro local.

No que diz respeito às relações com pessoas de outros grupos de casas e comunidades mais distantes, mesmo ocorrendo em ciclos mais curtos, as relações de ajuda têm efeitos similares. Embora sejam realizadas com pessoas mais distantes socialmente, elas servem para aproximar cada vez mais parceiros ocasionais de troca, podendo reforçar relações de consideração e até mesmo gerar outras de parentesco. Mauro Almeida já havia apontado em sua etnografia que grupos de casas formados por pessoas não aparentadas tendiam, ao longo do tempo, a estabelecer relações de compadrio e intercasamentos entre as casas (Almeida 1992). O ponto fundamental aqui é entender que relações de ajuda, além de permitirem a realização de tarefas materiais, servem para construir pessoas, criando e mantendo parcerias e alianças.

\section{Ajuda além}

Não tomar as relações de ajuda como desinteressadas e igualitárias e nem entendê-las como delimitadoras de um espaço social são dois pontos fundamentais para compreendê-las na bacia do rio Tejo. A aparente igualdade do que é trocado em relações de ajuda no interior de um grupo de casas resulta das condições e das precisões similares entre as casas que trocam. Uma casa que conhece a condição de outra, que a considera, não irá lhe fazer um pedido de ajuda demasiadamente custoso e nem fornecerá a alguém algo que possa comprometer o próprio funcionamento e a manutenção de sua casa. Quando procuramos exemplos de relações de ajuda com agentes externos - aqueles que têm melhores condições - fica evidente a correlação entre melhores condições e a participação mais generosa nas trocas. Hilarino, por exemplo, uma vez precisou fazer um empréstimo para uma construção que planejava. Não foi pedir o empréstimo a seu pai ou a seus irmãos, mas a um comerciante da cidade, alguém que ele sabia que tinha condição de fornecê-lo. Essa relação era tomada por ele como uma ajuda, com caracte- 
rísticas similares àquelas com as quais se engajou durante o ciclo agrícola. Vejamos outro exemplo de ajuda entre Hilarino e uma pessoa de longe de sua comunidade, de modo a evidenciar as similaridades nas relações:

Depois que o Domingos entrou [como presidente na Associação], [eu] só [trabalho] na diária mesmo. [...] Na hora que ele precisa de mim, eu ajudo, né? Tem vez que eu vou mais ele e ganho uma diária. Tem vez que acontece de eu ir, tipo assim, e já aconteceu várias vezes, eu vou e não recebo nada. Que não tem de onde pagar e precisa ir pra um canto, fazer uma reunião. Eu já fui mais ele, sem ganhar nada. Esse ano eu fui pra Rio Branco [representar a Associação], levei minha canoa até Cruzeiro [do Sul], fazendo frete, e não ganhei nada. Várias vezes já aconteceu isso. Agora, também quando vêm pessoas de fora, que é pra ir mais ele e o Figueiredo [do ICMBio], ele me coloca, né? (Hilarino Nogueira, entrevista, 14/02/2014).

Além de trabalhar como pequeno agricultor, Hilarino gerava parte de sua renda trabalhando como piloto de rabeta (canoa com motor de popa), em especial transportando agentes de governo e pesquisadores que visitam a Reserva Extrativista do Alto Juruá. Ele já havia sido piloto contratado da Associação de Agricultores e Seringueiros da Reserva Extrativista do Alto Juruá (ASAREAJ) em gestões passadas, mas foi "tirado" do cargo por um presidente que desconfiava que Hilarino estava "namorando" com sua mulher.

Com a eleição de Domingos, que presidia a Associação quando da realização da pesquisa de campo, Hilarino conseguiu estreitar suas relações com a ASAREAJ novamente. Só que a Associação não tinha mais a força política e econômica que tivera em outros tempos ${ }^{8}$ e Hilarino, às vezes, tinha que trabalhar sem saber quando receberia. Mas ele assim fazia confiando que Domingos iria chamá-lo quando a Associação intermediasse a contratação de pilotos para a realização de visitas do Ibama e do ICMBio, os órgãos governamentais responsáveis pela fiscalização e gestão da Reserva e que pagavam diárias muito superiores aos valores pagos entre moradores do Tejo para prestação de serviços de piloto - os valores das diárias cobradas do governo e de pesquisadores podiam ser até o dobro. Neste caso, o exemplo mostra que ter condição não é apenas ter dinheiro, mas capacidade de mobilizar pessoas e recursos. Também mostra como os habitantes do Tejo pessoalizam as relações de crédito e dívida não apenas quanto às casas vizinhas. O presidente da Associação se envolvia em relações de ajuda em seu nome, manejando recursos da Associação ao longo do tempo a partir das boas relações que mantinha com outros moradores da Reserva para fornecer ou requisitar crédito. 
O presidente da Associação operava como o chefe de uma casa, governando (ou administrando) fluxos de pessoas e coisas em redes de ajuda. Sua capacidade de endividamento, no entanto, era muito superior à de uma casa. A ASAREAJ, por ser a pessoa jurídica que representava os moradores da Reserva diante do Estado no acesso a projetos de desenvolvimento, tinha condição de se endividar com muitas pessoas. Em tempos de crise, ela podia recorrer à ajuda de moradores e depois pagar-lhes com recursos futuros que viesse a intermediar em projetos com o Estado, fossem diárias, cargos ou motores e ferramentas agrícolas. Em tempos de bonança, ela podia fazer o contrário, distribuindo bens e colocando os moradores em dívida com seu presidente. Dívida geralmente a ser paga nas próximas eleições para a presidência da associação na forma de apoio e votos.

Essa economia a partir da qual funcionava a ASAREAJ não era exclusiva dela. A mesma relação era mantida com os próprios representantes do Estado, nos mais diferentes níveis. Um voto era considerado pelos habitantes do rio Tejo como uma ajuda a políticos, que na "época da campanha" visitavam as comunidades para "pedir" votos dos quais necessitavam para manter sua própria condição de político. A "época da campanha" era tida como a única em que os políticos iam às comunidades do interior, visitando as casas das famílias mais pobres para pedir os votos daqueles que tinham condição de elegê-los. Posteriormente, esperava-se dos eleitos que, ao ocuparem as posições que lhes davam condição, retribuíssem o apoio prestado na "época da campanha" distribuindo bens ou cargos para as famílias que os haviam elegido. Relações de ajuda mútua eram também mantidas nos comércios da sede do município de Marechal Thaumaturgo. Havia um sistema de contas em cada comércio que se assemelhava àquele praticado pelos patrões nos tempos dos seringais, no qual cada casa tinha sua própria conta, identificada com o nome do chefe da casa, e que registrava saldos e dívidas de sua família, possibilitando empréstimos nos períodos de necessidade.

\section{Raízes históricas}

Mauro Almeida descreveu que nos antigos seringais do rio Tejo a relação comercial entre seringueiros e patrões era marcada por um elo moral, e que a permanência dos seringueiros nos seringais não era forçada pelas dívidas que contraíam e por violência que coibia sua saída (a possibilidade de fuga sempre existiu). Assim, as maiores revoltas de seringueiros não ocorriam pela cobrança de dívidas, mas por atitudes que julgavam imorais, que desrespeitavam a integridade das pessoas, como violência extrema, 
falta de estiva ${ }^{9}$ no barracão ou de assistência médica por parte do patrão, fosse por ausência de remédios ou pela negativa de providenciar passagem de doentes graves para a cidade (Almeida 1992:156). Do ponto de vista dos seringueiros, patrões tinham responsabilidades para com eles. Essa obrigação moral estava relacionada à posição social ocupada pelos patrões: havia coisas que apenas eles podiam fornecer para que os seringueiros mantivessem uma vida considerada digna. Era por esta razão que existiam, aos olhos dos seringueiros, bons e maus patrões. Seu Milton, antigo morador do rio Tejo, narrou para Mariana Pantoja Franco sua experiência com diferentes patrões da seguinte maneira:

Aí passou esses outros patrões que tudo só deixava a gente na mal. Mas aí foi o tempo que chegou o Epaminondas, aí eu fiquei bem aprumadinho. Quando ele saiu, foi embora, eu fiquei bem aprumado: fiquei com gado, com motor, com a oficina. Ele procurou me ajudar no quanto pôde (Pantoja Franco 2008:320-321).

A diferenciação entre um bom e um mau patrão dependia de alguns fatores, por exemplo, não deixar faltar mercadorias e não explorar seringueiros além daquilo que eles próprios aceitavam, estabelecendo relações consideradas justas. Havia aqueles que ajudavam os seringueiros, mantendo as mercadorias necessárias e o acesso a elas, e os que apenas queriam explorá-los. Com os bons patrões, seringueiros poderiam até cultivar amizades, como foi o caso de seu Milton com Epaminondas.

Essa mesma estrutura de relações se replicou em um projeto de desenvolvimento gerenciado pelos habitantes da região após a retirada dos patrões e a criação da Reserva Extrativista do Alto Juruá. De modo a criar uma alternativa que substituísse os barracões em seu papel de aviar seringueiros com o abastecimento de mercadorias ao longo do ano, a serem pagas com a borracha no fim da safra, foram estabelecidas diversas cantinas, administradas por moradores da região chamados gerentes. Mas a experiência das cantinas não durou muito tempo. Após alguns anos, elas foram sendo fechadas por incapacidade de pagamento das dívidas que contraíam com os fornecedores de mercadorias, por sua vez causadas pela incapacidade de muitos seringueiros de pagarem suas dívidas. Seringueiros tomavam mercadorias ao longo do ano nas cantinas para pagá-las apenas ao fim do ciclo de produção da borracha. Mas dado o contexto de crise da borracha, muitos deles não conseguiam quitar seus compromissos em função do baixo preço pago na produção no final do ano. Por sua vez, no contexto de alta inflação que o país atravessava no início dos anos 1990, o endividamento da cantina com fornecedores crescia ano a ano, tornando-as inviáveis economicamente. 
Revelador nesse processo é saber por que os gerentes não regulavam o aumento do endividamento de seus clientes que não conseguiam pagar dívidas anteriores. Isto significaria negar o abastecimento de mercadoria a seus vizinhos e parentes, deixando os gerentes com um dilema: mesmo sabendo que muitos seringueiros seriam incapazes de quitar seus débitos, eles eram os únicos que tinham condição de adiantar mercadoria para aquelas famílias que enfrentavam uma situação econômica difícil. Alçados por seus vizinhos e parentes a um cargo que lhes garantia melhor condição no que se refere ao poder de distribuir bens, os gerentes se encontravam amarrados à mesma rede de relações de um político. Ambos enfrentavam o dilema de gerenciar recursos advindos do Estado (no caso das cantinas, grande parte dos recursos eram provenientes do BNDES) diante de uma economia que pressionava aqueles em melhor condição a darem assistência aos seus parceiros de troca. Como descreveu Mariana Pantoja Franco sobre esse período, a escolha dos gerentes pelos vizinhos "foi quase sempre feita com base na 'confiança' neles depositada por suas 'comunidades'" (Pantoja Franco 1994:195). Por isso, "ao fiar a 'mercadoria'", o gerente "'assistia' à 'comunidade' e contraprestava 'confiança' nele depositada" (:199). Sobre o mesmo episódio, Eliza Costa escreveu:

Ou seja, o gerente, para continuar sendo gerente, precisava entregar mercadorias fiado e, com isso, praticamente inviabilizava a existência da cantina, pois em época de alta inflação e baixos preços da borracha era quase inevitável que a maioria não conseguisse dar conta de suas dívidas (Costa 2010:221-222).

\section{Uma economia redistributiva}

Há uma continuidade histórica na relação dos habitantes do Tejo com seus representantes políticos e seus parceiros comerciais da atualidade. Relações de troca fundamentadas em moral continuam a vigorar e, embora com mudanças nos atores, o princípio de que aquele que tem acesso a bens e serviços deve ajudar o que necessita deles ainda pauta relações de troca em diferentes níveis. O pai e a sogra de Hilarino, por exemplo, compravam na maioria das vezes no mesmo comércio na sede de Marechal Thaumaturgo, onde mantinham suas contas. A sogra de Hilarino, inclusive, se referia ao dono do comércio como "meu patrão", já que a relação comercial mais recente se assemelhava à antiga. ${ }^{10}$ Para eles, a parceria comercial era uma forma de manter uma ligação próxima com o comerciante, de modo que tivessem crédito disponível quando precisassem comprar algo mas não tivessem dinheiro. 
Este tipo de relação era entendida como vantajosa para as duas partes, pois todo comércio tem também necessidade de freguesia para funcionar. Por um lado, os clientes esperavam fornecimento de mercadorias adiantadas em suas contas nos períodos em que estivessem passando por necessidades. Por outro, os comerciantes garantiam clientela a partir de vínculos de confiança que permitiam até mesmo que clientes que viviam no alto dos rios deixassem seus cartões e senhas de banco para recebimento de benefícios sociais nas mãos desses comerciantes. Nesses casos, os comerciantes não apenas forneciam créditos e mercadorias, como também administravam saldos positivos de muitas pessoas, a exemplo do que ocorria nas contas dos seringais (a diferença principal entre as contas dos barracões dos patrões e as contas dos comércios da vila era que, neste último caso, não havia um acordo entre as partes para compra exclusiva. ${ }^{11}$ No entanto, o que se via na prática era que os habitantes do Tejo tendiam a manter parceiros de troca preferenciais dentre os vários comércios da sede municipal).

Nesse modelo econômico, o que se deve observar em busca da justiça das trocas e o que caracteriza a relação como ajuda são a condição e a precisão dos sujeitos dentro de um universo estruturado em hierarquias e em condições de maior ou menor poder. A ajuda, portanto, depende também da consideração de condições. Um dos desdobramentos da interpretação das trocas nesses moldes é que, quando a consideração pela precisão se encontra com as condições dos sujeitos, a relação de ajuda imprime um caráter redistributivo às trocas.

Há uma tensão constante colocada pela assimetria entre a condição e a precisão que tenta ser resolvida com apelos à redistribuição. Pessoas com condições materiais semelhantes trocarão bens e serviços com valores aproximados. Já de pessoas com condições materiais melhores espera-se uma participação mais generosa nas trocas. Se dois vizinhos trocam dias de trabalho entre suas casas é porque esta é a condição de ambos. Tal igualdade de poder e necessidades faz a equivalência da troca tornar-se justa.

Já uma troca com um político busca justiça pela oferta de coisas distintas associadas à diferença entre a condição dele e a da outra pessoa. De um político se espera a doação de bens de maior valor, como motores, geradores, ou mesmo empregos, que só os políticos são capazes de mobilizar para troca. Um político, na condição de quem tem acesso às verbas do Estado, dispõe desse dinheiro em benefício daqueles que o colocaram nessa condição. É inconcebível para os habitantes do Tejo retribuir um motor doado por um político com um objeto de igual valor. Retribuirão com apoio em campanhas e, eventualmente, votos. Na visão local, o papel do político eleito é, acima de tudo, ajudar as pessoas, retribuindo os votos, seja através de ações legais 
ou ilegais. A relação de ajuda, assim, se pauta por uma espécie de economia política que nem sempre está de acordo com a economia política do Estado democrático. Um voto comprado e não pago não é julgado como má conduta por desrespeitar leis, mas por desrespeitar as relações entre as pessoas em uma economia fundamentada em princípios morais de reciprocidade e redistribuição.

Dizer que a economia das trocas dos habitantes do Tejo tem raízes históricas e que fornece uma visão particular para as relações com comerciantes e políticos não significa aceitar de maneira acrítica tais relações. Seria tão errado quanto olhar para essa economia de forma condescendente, como uma economia igualitária agora corrompida pelo poder das elites locais. As pessoas têm conhecimento e senso crítico suficientes para compreender o que ocorre nos contatos com comerciantes e políticos. No caso da política, por exemplo, os habitantes do Tejo demonstram engajamento e participação ativos nos processos democráticos. Como registrou Eliza Costa (2010), a "política" é um assunto cotidiano entre os habitantes do alto Juruá, que têm alto grau de consciência e participação no funcionamento dos diferentes níveis de governo. O fato de seu comportamento ser pautado por uma perspectiva particular sobre as trocas não significa que eles não compreendam os supostos pactos do Estado democrático. A diferença é que suas perspectivas sobre justiça das trocas imprimem dinâmicas peculiares à prática política na região. Uma moradora, por exemplo, pode ameaçar o prefeito de denunciá-lo ao Ministério Público por compra de voto que ela própria realizou, mas que ele não retribuiu com o emprego a ela prometido (Rezende 2016:166). Ela é capaz de utilizar uma lei para pressionar um agente de estado a cometer uma segunda ilegalidade tendo em vista a efetivação de uma promessa de ajuda. Os habitantes do Tejo não apenas conhecem as duas linguagens (do contrato e da reciprocidade), como também transitam entre elas.

É importante ressaltar que economias com características similares foram descritas em outros contextos rurais do Brasil, como no trabalho de Afrânio Garcia Jr. sobre pequenos produtores de Pernambuco, no qual figuras políticas aparecem como responsáveis pelas mais pobres: "É também nesse sentido que [o presidente e o governo] são considerados como responsáveis por ajudar a quem precisa, pois são os que mais têm; portanto, os que mais podem dar" (Garcia Jr. 1983:95); ou de Marcos Lanna sobre o pequeno município rural de São Bento do Norte (RN), que chegou a sugerir que relações desse tipo moldavam a estrutura do poder político e econômico, imprimindo uma dinâmica peculiar ao Estado no Brasil: "O poder é delegado de cima ao mesmo tempo em que é também gerado localmente, ou de baixo para cima, sem que haja contradição entre uma macro e uma microfísica do poder" (Lanna 1995:31-32). 


\section{O valor da ajuda}

Uma questão levantada pelas proposições acima é: se há relações de ajuda com comerciantes e com políticos, porque é tão comum encontrar em comunidades amazônicas reiteradas queixas sobre a atitude deles, como se fossem atores dos quais se deve desconfiar e evitar? (Harris 2000). Um dos motivos parece ser a limitação material que políticos encontram para responder aos anseios redistributivos da economia da ajuda. Ligados a uma estrutura de Estado com recursos restritos e com órgãos de controle, eles nem sempre podem distribuir todos os bens e cargos prometidos. Do mesmo modo, comerciantes, além de recursos finitos, estão comprometidos com sua capacidade de produzir lucro em curto e médio prazos. Políticos e comerciantes transitam e manejam a economia de ajuda, mas estão também comprometidos com outros objetivos, o que faz com que seus comportamentos neguem com certa frequência a reciprocidade e a redistribuição exigidas em determinadas situações. Isso faz com que suas atitudes sejam muitas vezes entendidas como formas de desconsideração ou, ainda, de humilhação das pessoas que mais precisam e que a eles recorrem. ${ }^{12}$

Resulta desta situação uma imagem negativa de políticos e comerciantes enquanto classes de pessoas. Mas, no nível pessoal, formam-se parcerias de determinadas famílias com certos políticos e comerciantes. Essas parcerias costumam durar até que aquele que tem mais condição negue um bem, emprego ou empréstimo ao outro. Assim, os habitantes do Tejo são críticos quando se pergunta sobre figuras genéricas, como o político e o comerciante, mas todos têm um político e um comerciante de confiança, a quem procuram quando se encontram em uma situação de necessidade e com quem mantêm relações especiais de voto e compras.

A exemplo do que ocorre no interior das comunidades, o que está também em jogo na relação com políticos e comerciantes é o olhar pelas necessidades do outro, a consideração por aquele que precisa e que recorre a um pedido de ajuda. Mais importante do que o valor dos objetos trocados, o resultado da relação de ajuda é a conexão que se cria entre os sujeitos e que aumenta na medida em que trocas nesses moldes se sucedem (ou que diminui e se rompe quando a cadeia de trocas se interrompe). Não se espera que a relação de ajuda seja uma troca de soma zero, na qual os indivíduos, ao fim, não têm mais nada que os conecte. A ajuda é um tipo de relação de troca que resulta na disponibilidade dos sujeitos para novas relações de troca. Há um saldo positivo resultante da relação e que orientará trocas futuras. A questão com políticos e comerciantes é que nem sempre eles fornecem o que deles se espera, causando grandes frustrações. 
Este ponto é fundamental para compreender o cerne das relações de ajuda na bacia do rio Tejo: mais do que permitir a realização de tarefas materiais e a consequente produção de coisas, elas criam relações entre pessoas e efeitos sobre elas. Fazendo um paralelo com os exemplos de dádivas examinados por Mauss, nos quais a troca de dons recíprocos estava relacionada à agência de uma "alma" que os objetos trocados carregavam consigo e que os faziam circular, fosse a "alma" de alguma divindade ou do próprio doador do objeto, na bacia do rio Tejo essa "alma" deve ser procurada em outro lugar. As relações de ajuda não pressupõem um princípio animador intrínseco aos objetos que faça com que eles sejam trocados novamente. Tampouco dependem de objetos com propriedades especiais.

A reciprocidade opera diretamente na relação entre as pessoas, relativizando o valor dos objetos trocados. Ela é avaliada na medida em que afeta as pessoas e suas ações no futuro, deixando os caminhos abertos para novas trocas. Ela não se dá pela existência de um princípio animador contido nos objetos, mas pelos efeitos e afetos que criam nas pessoas e que animam a continuidade da relação. Se realmente a marca de uma relação de reciprocidade é a existência de um terceiro elemento "de natureza ontológica" (Sabourin 2008:134), no caso da ajuda esse elemento pode ser a consideração, tida como uma força que influencia a tomada de decisões e coloca sob julgamento moral a ação individual a partir de uma perspectiva partilhada sobre justiça e sobre como a vida social deve se desenrolar.

Outro contraste possível de se fazer quanto ao ensaio de Mauss é sobre seus apontamentos em relação ao potlatch sobre as retribuições de dádivas acrescidas de juros ${ }_{1}^{13}$ razão pela qual uma sequência de trocas resultaria em incrementos nos valores totais dos objetos trocados. No caso do Tejo, as trocas não precisam envolver valores equivalentes ou crescentes para serem tidas como relações de ajuda. A um dia de trabalho se retribui com um dia de trabalho, e de alguém que se hospeda em uma casa espera-se em retribuição hospedagem ou outro tipo qualquer de ajuda, e não necessariamente um jantar e uma rede melhores do que os que foram oferecidos. Embora o escalonamento no valor dos objetos trocados não esteja presente, é possível dizer que há neste tipo de relação outro tipo de "juros". Relações de ajuda também resultam em acúmulos ao longo de cadeias de trocas, só que os valores acumulados são a própria relação construída entre as pessoas e o aumento da consideração entre elas. Ao invés de gerar acúmulos investidos em objetos, a ajuda gera acúmulos de relações nas pessoas. ${ }^{14}$ Assim, poderíamos pensar a consideração tanto como princípio animador quanto como valor resultante das trocas, perfazendo um circuito de trocas que produz relações nos termos consideração -> ajuda $->$ consideração'. A produção 
do valor não estaria evidenciada nos objetos produzidos ou circulados pela troca, mas no afeto criado entre as pessoas que se relacionam.

Neste ponto há uma ponte de diálogo com a obra de Nancy Munn sobre Gawa, na Papua Nova Guiné. Ela defendeu uma interpretação das relações de troca que olhava para a constituição "intersubjetiva" dos sujeitos ao longo dessas relações e que afetava suas mentes e suas ações futuras. Ao tratar do kula, Munn divergiu da interpretação de Mauss, observando que o circuito de trocas produz valor não na forma material (aumentando o valor total dos objetos trocados), mas na forma pessoal, fornecendo a sujeitos individuais e coletivos poder de ação sobre os demais, manifestado na "fama". Ações com valor positivo resultam na potência para influenciar outras pessoas. Aplicando o conjunto de conceitos apresentados por Munn para pensar o caso do Tejo, a consideração como resultado de relações de ajuda seria um tipo de valor no sentido em que possibilitaria a "extensão do espaço-tempo" de um sujeito, uma "capacidade de desenvolver relações espaço-temporais que vão além de si próprio, ou que expande dimensões de controle espaço-temporal de um ator" (Munn 1986:11). É a capacidade de fazer outras pessoas agirem em favor de si mesmo através dos efeitos gerados pelas próprias ações.

David Graeber, ao analisar a obra de Munn, ressaltou a originalidade de uma abordagem deste tipo, que permite a uma análise sobre relações de troca escapar das dicotomias entre dádivas e mercadorias. "Ao invés de ter que escolher entre o desejo por objetos e a importância das relações humanas, agora se pode ver ambos como refração de uma mesma coisa" (Graeber 2001:45). O foco do valor, neste caso, passa a ser o interesse humano em gerar determinadas relações. E as ações passam a ser avaliadas a partir de suas consequências em gerar as relações esperadas, podendo resultar em ações com valores positivos ou negativos.

Esta perspectiva sobre o valor é útil na medida em que permite tratar de situações nas quais o valor das ações se manifesta no acúmulo de relações nas pessoas (como a fama ou a consideração). O que a etnografia do Tejo, interpretada nessas bases, demonstra é a consideração como um valor fundamental das relações humanas. Esse valor é criado a partir de relações de reciprocidade que colocam em avaliação a consideração sempre que se inicia um novo ciclo de troca.

Situação com características similares nos foi descrita por Benoît de L'Estoile, embora em termos teóricos distintos. Analisando a vida de "pobres" da Zona da Mata pernambucana, ele defendeu que a incerteza, enquanto aspecto estrutural da vida local, levava a uma valorização maior das relações de amizade, das quais deriva apoio em momentos de necessidade, do que 
da posse de dinheiro. Mas a incerteza está colocada mesmo nas relações de amizade, já que a prestação de uma ajuda a alguém leva sempre a um período de "espera", no qual a incerteza da retribuição se coloca (L'Estoile 2014:S66). A espera, enquanto um aspecto central da vida estruturada em torno da incerteza (não só em relação à reciprocidade, mas também às condições materiais), torna-se parte de um "quadro de referência" para a ação dos sujeitos, fornecendo um "horizonte de expectativas" que orienta moralmente as ações para além dos domínios da economia. É nesse contexto que relações de ajuda, amizade e consideração ganham sentido: "A amizade 'verdadeira' é um relacionamento de longo prazo que envolve a boa vontade (se não a possibilidade real) de ajudar, junto com a consideração mútua" (:S70).

\section{Considerações finais}

Os trabalhos citados na introdução apresentaram algumas das principais características das relações de ajuda, apontando a centralidade que elas têm na vida de diversas comunidades tradicionais amazônicas e como estão ligadas a fatores econômicos, políticos, territoriais e ao parentesco. Com o relato de exemplos do rio Tejo, procurou-se detalhar e adicionar novos elementos ao debate sobre as relações de ajuda na Amazônia brasileira.

Os exemplos citados sugerem que as relações de ajuda não são definidas ou se diferenciam das demais formas de troca apenas por suas características materiais. Embora a capacidade de fornecer ajuda seja limitada pelas condições materiais das casas, ao mesmo tempo em que as casas dependem de ajuda para realizar suas atividades, essas relações vão além, construindo e atualizando constantemente outras relações. É nesse sentido que os habitantes do Tejo se utilizam do termo ajuda abarcando várias trocas que se diferenciam do ponto de vista material. Ao se referirem a distintas trocas materiais como ajuda, os habitantes do Tejo evidenciam as relações construídas com essas trocas e que termos como empeleita e troca de dias são incapazes de comunicar. Do potencial da ajuda de gerar relações entre pessoas deriva a possibilidade de ela englobar nos discursos uma série de formas de trocas com características materiais distintas. Quando alguém caracteriza uma troca como ajuda, está se referindo a uma relação que cria consideração através do apoio que um parceiro dá ao outro. Esta consideração será um elemento orientador das ações futuras desses parceiros de troca, reforçando laços e gerando parcerias preferenciais.

Além disso, os exemplos do Tejo não permitem concluir que a ajuda delimita o espaço dos grupos de casas ou das comunidades ou é delimitada 
por ela. Antes, a ajuda funciona como um elemento agregador nesses espaços por afetar as escolhas das pessoas, criando e mantendo boas relações. Mas ela é apenas a face positiva de uma economia que valora as ações de acordo com a consideração e a desconsideração gerada nas relações de troca. E quando as relações incorrem em desconsideração, não há ajuda. Tem-se o afastamento social dos sujeitos, o evitamento e a desconfiança para o estabelecimento de novas relações. Ao invés da ideia de relações de ajuda limitadas a espaços comunitários ou tradicionais, a etnografia do Tejo aponta (ao lado de trabalhos sobre outras regiões do Brasil) para a possibilidade de repensar a ajuda como um componente central dos modos de vida locais que pressionam o funcionamento do mercado e do Estado em um sentido diferente daquele esperado pela teoria econômica e política. Ao fundamentar a justiça e a construção da consideração na relação entre distintas precisões e condições dos parceiros que trocam, a economia pautada pela ajuda pressiona o Estado e o mercado em direção a práticas redistributivas.

Do ponto de vista histórico, dizer que a ajuda se fundamenta em relações de consideração tem várias implicações para a compreensão dos modos de vida de comunidades amazônicas. Uma delas é deslocar a análise da história desses coletivos de pontos de vista meramente produtivos, que interpretam o modo de vida das comunidades tradicionais a partir da adaptação ao ambiente amazônico e a ciclos econômicos que se sucedem (crítica presente em Adams, Murrieta \& Neves 2006). A existência de raízes históricas nas relações de ajuda no Tejo e as evidências de que relações similares perduram no tempo nos fornecem pistas para repensar o quanto ideias particulares sobre economia e política impactaram e ainda impactam os mais diversos aspectos da vida cotidiana ao longo da história. As revoltas de seringueiros contra patrões, fundamentadas em avaliações sobre práticas consideradas injustas, são apenas um exemplo de como a história de comunidades amazônicas está marcada por perspectivas particulares sobre a vida social que podem resultar em impactos históricos de longo prazo.

Por fim, uma análise das trocas assentada nas expectativas e nos sentimentos dos sujeitos não precisa deixar de lado explicações acerca do mundo material. Ao contrário, tal proposta passa a compreender o próprio afeto entre os sujeitos como materializado em suas ações. Tem-se uma análise do valor que toma as "superestruturas" como elementos tão materiais quanto as "infraestruturas" (Graeber 2001:40, 54). No caso do Tejo, a consideração aparece como resultado materializado na constituição das próprias pessoas, afetando a circulação delas e de seus bens, bem como sua ocupação no espaço, orientando a formação dos grupos de casas, responsáveis pelo controle e a manutenção de meios de produção coletivos (tais como casas de 
farinha, campos de criação de gado e caminhos). O alto grau de consideração entre os parceiros de troca nesses espaços permite não apenas a convivência e a partilha de bens, mas também ciclos mais longos de retribuição, já que, enquanto uma relação que afeta as escolhas dos sujeitos, a consideração diminui as incertezas relativas ao comportamento dos parceiros.

Recebido em 02 de novembro de 2016

Aprovado em 23 de maio de 2017

Roberto Sanches Rezende é doutor em Antropologia Social pela Universidade Estadual de Campinas (Unicamp) e pós-doutorando da Universidade Federal de São Carlos (UFSCar), São Carlos, SP, Brasil. E-mail: <robertorezende@ gmail.com>

\section{Notas}

* Por ocasião da realização da pesquisa, o autor realizava seu doutorado na Universidade Estadual de Campinas.

1 A Reserva Extrativista do Alto Juruá foi a primeira unidade de conservação do tipo criada no país. Para um relato do processo histórico de sua criação, conferir Almeida (2004).

2 Os dados sobre a média de 18 casas por comunidade provém de pesquisa de campo para a realização do Plano de Manejo Participativo da Reserva Extrativista do Alto Juruá, realizada em 2010. Os trabalhos foram coordenados pelo antropólogo Augusto Postigo e o Plano ainda não foi publicado pelo órgão gestor responsável pela Reserva.

3 A partir de meados dos anos 1990, para instalar escolas, postos de saúde, abastecimento de energia elétrica e meios de comunicação a baixo custo, a prefeitura e outras instituições de Marechal Thaumaturgo incentivaram a aglomeração em poucos locais. Nesse mesmo período houve uma queda no preço da borracha que levou a uma transição das atividades produtivas para a agricultura. Assim, seringueiros saíram dos centros das matas, onde estavam espalhadas naturalmente as seringueiras, para as margens dos rios, onde se formaram as comunidades (Costa 2010; Rezende 2016).

4 A pesquisa foi realizada com apoio da Fundação de Amparo à Pesquisa do Estado de São Paulo (Fapesp), processo no 2010/10454-0. O texto aqui apresentado é uma revisão ampliada do quinto capítulo da tese de doutorado defendida no Programa 
de Pós-Graduação em Antropologia Social da Universidade Estadual de Campinas. Além da pesquisa de campo para o doutorado, a etnografia se apoia em dados de diversas outras viagens de campo ao alto Juruá, realizadas desde 2006.

5 Uma análise detalhada das etapas do ciclo agrícola de pequenos agricultores do alto Juruá pode ser vista em Pantoja Franco et al. (2002).

6 Em atividades que não exigiam muita força, como a colheita do arroz, os trabalhos de homens e mulheres podiam ser tomados como equivalentes, aceitandose o câmbio entre eles. Em atividades como a derrubada da mata, apenas homens participavam.

7 Não há espaço aqui para detalhar como a criação cultiva consideração e o hábito da ajuda em crianças. Basta dizer que, à medida que uma criança vai desenvolvendo capacidades produtivas, passa a apoiar os serviços de funcionamento e manutenção da casa, gradativamente assumindo funções como carregar água, limpar a casa, lavar a louça, trabalhar nos roçados e cozinhar. Esse apoio é sempre verbalizado pelos pais como "ajuda" a casa. Um relato mais detalhado sobre como a socialização de crianças passa pela reprodução de relações de ajuda pode ser encontrado em Rezende (2016, capítulo 6).

8 Para um relato de como a ASAREAJ entrou em crise política e econômica, conferir o trabalho de Eliza Costa (2010).

9 Estiva é o termo utilizado para se referir a um conjunto de mercadorias consideradas como essenciais para o funcionamento de uma casa: sal, sabão, óleo, açúcar e munição (Almeida 1992:120)

10 Além disso, algumas pessoas que moravam distante da vila mantinham seus cartões para recebimento de benefícios sociais e aposentadorias nas mãos de comerciantes. Isto significa que uma conta podia ser não apenas uma lista de débitos financeiros em função de crédito pessoal, mas também de créditos financeiros em função de crédito (confiança) depositado na relação com o comerciante.

11 No caso dos patrões havia ainda a renda pelas estradas de seringa, que eram tidas como de sua propriedade. O suporte do Estado ao cumprimento dos acordos e dos contratos (ainda que informais) e o uso da violência policial para a cobrança de dívidas, no entanto, é são possíveis nas duas situações (barracões e comércios).

12 Como lembram Pina-Cabral e Silva, relações tidas como de caciquismo podem ser formuladas, e no Tejo o são, "em termos de atenção, de assumir e de consideração" (Pina-Cabral \& Silva 2013:42).

13 Ao tratar do potlatch como um sistema agonístico, Mauss afirmou que "normalmente, o potlatch deve sempre ser retribuído com juros, aliás, toda dádiva deve ser retribuída dessa forma. As taxas são em geral de 30\% a 100\% ao ano" (Mauss 2003:249).

14 Ao invés de "juros", poderíamos falar também em "créditos" resultantes das relações de troca, uma vez que o resultado é uma abertura para novos endividamentos no futuro. 


\section{Referências bibliográficas}

ADAMS, Cristina; MURRIETA, Rui; NEVES, Walter A (orgs.). 2006. Sociedades caboclas amazônicas: modernidade e invisibilidade. São Paulo: Annablume.

ALMEIDA, Mauro W. B. de. 1992. Rubber tappers of the upper Juruá river, Brazil. The making of a forest peasant economy. PhD Thesis, University of Cambridge.

. 2004. "Direitos à floresta e ambientalismo: seringueiros e suas lutas". Revista Brasileira de Ciências Sociais, 19(55): 33-53.

COSTA, Eliza. M. L. 2010. Uma floresta politizada: relações políticas na Reserva Extrativista do Alto Juruá, Acre (1994-2002). Tese de Doutorado, Unicamp.

FRAXE, Therezinha de J. P. 2004. Cultura cabocla-ribeirinha: mitos, lendas e transculturalidade. São Paulo: Annablume.

GARCIA JR., Afrânio. 1983. Terra de trabalho. Rio de Janeiro: Paz e Terra.

GRAEBER, David. 2001. Toward an anthropological theory of value: the false coin of our own dreams. Basingstoke, Reino Unido: Palgrave Macmillan.

HARRIS, Mark. 2000. Life on the Amazon: the anthropology of a Brazilian peasant village. Oxford: Oxford University Press.

LANNA, Marcos. 1995. A dívida divina: troca e patronagem no Nordeste brasileiro. Campinas: Editora da Unicamp.

LIMA-AYRES, Deborah M. 1992. The social category caboclo: history, social organization, identity and outsider's social classification of the rural population of an amazonian region (the Middle Solimões). Doctoral Dissertation, University of Cambridge.
L' ESTOILE, Benoît de. 2014. “Money is good but a friend is better: uncertainity orientation to the future, and 'the economy'". Current Anthropology, 55(Supplement 9): S62-S73.

MACHADO, Juliana. 2012. Lugares de gente: mulheres, plantas e redes de troca no delta amazônico. Tese de Doutorado, UFRJ.

MAUSS, Marcel. 2003. "Ensaio sobre a dádiva". In: Marcel Mauss: sociologia e antropologia. São Paulo: Cosac \& Naify: 183-314.

MUNN, Nancy D. 1986. The fame of Gawa: a symbolic study of value transformation in a Massim society (Papua New Guinea). Cambridge: Cambridge University Press.

PANTOJA FRANCO, Mariana C. 1994. "Seringueiros e cooperativismo: o fetichismo das 'mercadorias' nos seringais do Alto Juruá". In: Leonilde Medeiros et al., Assentamentos rurais: uma visão multidisciplinar. São Paulo: Editora da Unesp.

. 2008. Os Milton: cem anos de história nos seringais. Recife: Fundação Joaquim Nabuco.

PANTOJA FRANCO, Mariana C. et al. 2002. "Botar roçados". In: Manuela C. da Cunha \& Mauro W. B. de Almeida (orgs.), Enciclopédia da floresta. São Paulo: Companhia das Letras: 249-283.

PINA-CABRAL, João D. \& SILVA, Vanda. A. 2013. Gente livre: consideração e pessoa no Baixo Sul da Bahia. São Paulo: Editora Terceiro Nome.

REZENDE, Roberto. 2016. Camponeses da bacia do rio Tejo: economia, política e afeto na Amazônia. Tese de Doutorado, Unicamp. 
SABOURIN, Eric. 2008. "Marcel Mauss: da dádiva à questão da reciprocidade". Revista Brasileira de Ciências Sociais, 23(66): 131-138.

SILVA, Elane C. L. 2007. A dinâmica das relações comunitárias na Amazônia: estudo de caso das formas de ajuda mútua praticadas na comunidade ribeirinha de Tauaru no município de Tabatinga-AM. Dissertação de Mestrado, UFAM.
SILVA, Simone S. C. 2010. "Rede social e papéis de gênero de casais ribeirinhos de uma comunidade amazônica". Psicologia: Teoria e Pesquisa, 26(4): 605-612.

WAGLEY, Charles. 1976. Amazon town: a study of man in the tropics. Oxford: Oxford University Press. 


\section{CARACTERÍSTICAS DAS RELAÇÕES \\ DE AJUDA NA AMAZÔNIA \\ BRASILEIRA: APONTAMENTOS \\ A PARTIR DO ESTUDO DOS \\ HABITANTES DA BACIA DO RIO \\ TEJ O, ACRE}

\section{Resumo}

Baseado em etnografia, este artigo descreve as relações de ajuda entre habitantes da bacia do rio Tejo, um afluente do alto Juruá, no extremo oeste do estado do Acre. Após introduzir como o tema da ajuda entre comunidades tradicionais da Amazônia brasileira foi tratado em trabalhos anteriores, que ressaltaram as características de dádiva associadas à ajuda e sua correlação com o parentesco e a territorialidade, passa-se à análise de como as relações de ajuda constroem e atualizam outras relações entre os parceiros de troca no Tejo. O artigo ainda explora como as relações de ajuda se expandem para além do limite das comunidades, influenciando a economia e a política regionais em direção a práticas redistributivas a partir de uma perspectiva particular sobre o valor produzido nas trocas.

Palavras-chave: Troca; Camponeses da Amazônia; Economia Doméstica.
CHARACTERISTICS OF AJUDA

RELATIONS IN THE BRAZILIAN

AMAZON: NOTES FROM THE STUDY OF THE INHABITANTS OF THE TEJ O

RIVER BASIN, ACRE

\section{Abstract}

The article describes ajuda (help) relations among inhabitants of the Tejo River Basin, on the Upper Juruá River, in southeastern Acre, Brazil. It begins with a summary of previous works on Amazonian communities and how they have described ajuda relations as gift relations with connection to kinship and territoriality. Based on ethnographic data, the article argues that ajuda goes beyond the material aspects of exchange, creating and maintaining relations between exchange partners. They also go beyond communities' physical boundaries and impact the regional economy and politics as redistributive practices, providing perspective on the value produced in exchange.

Key words: Exchange; Amazonian Peasants; Household Economy. 
CARACTERÍSTICAS DE LAS

RELACIONES DE AYUDA EN LA

AMAZONÍA BRASILEÑA: APUNTES

A PARTIR DEL ESTUDIO DE LOS

HABITANTES DE LA CUENCA DEL

RÍO TEJO, ACRE

\section{Resumen}

Basado en datos etnográficos, este artículo describe las relaciones de "ayuda" entre habitantes de la cuenca del río Tejo, un afluente del alto Juruá, en el extremo oeste del estado de Acre - Brasil. En un primer momento, discuto como el tema de la ayuda entre comunidades tradicionales de la Amazonía brasileña fue abordado en trabajos anteriores, que resaltaron las características del intercambio o trueque asociándolo a la ayuda y su correlación con el parentesco y la territorialidad. Posteriormente paso al análisis sobre la manera en que las relaciones de ayuda construyen y actualizan otras relaciones entre quienes intervienen en el trueque o intercambio en el Tejo. El artículo también explora la forma en que las relaciones de ayuda se expanden más allá del límite de las comunidades, influenciando la economía y la política regionales en dirección a prácticas redistribuidas a partir de una perspectiva particular sobre el valor producido en los intercambios.

Palabras-clave: In tercambio, Campesinos de la Amazonía, Economía Doméstica. 